\title{
CORPUS Corpus
}

Archivos virtuales de la alteridad americana

Vol. 7, No 2 | 2017

Julio / Diciembre 2017

Reseña de Letra de Índios. Cultura escrita, comunicação e memória indígena nas Reduções do Paraguai, de Eduardo Neumann. Nhanduti Editora, São Bernardo do Campo, 2015, 240 páginas

Fabián R. Vega

\section{CpenEdition}

\section{Journals}

Electronic version

URL: http://journals.openedition.org/corpusarchivos/1903

DOI: 10.4000/corpusarchivos. 1903

ISSN: 1853-8037

\section{Publisher}

Diego Escolar

Electronic reference

Fabián R. Vega, « Reseña de Letra de Índios. Cultura escrita, comunicação e memória indígena nas Reduções do Paraguai, de Eduardo Neumann. Nhanduti Editora, São Bernardo do Campo, 2015, 240 páginas », Corpus [En línea], Vol. 7, No 2 | 2017, Publicado el 05 diciembre 2017, consultado el 24 abril 2019. URL : http://journals.openedition.org/corpusarchivos/1903; DOI : 10.4000/ corpusarchivos.1903

This text was automatically generated on 24 April 2019.

Licencia Creative Commons: Atribución-NoComercial 2.5 Argentina (CC BY-NC 2.5 AR) 


\section{Reseña de Letra de Índios. Cultura escrita, comunicação e memória indígena nas Reduções do Paraguai, de Eduardo Neumann. Nhanduti Editora, São Bernardo do Campo, 2015, 240 páginas}

Fabián R. Vega

1 Desde hace más de una década, el historiador brasileño Eduardo Neumann, actualmente profesor en la Universidad Federal de Rio Grande do Sul, ha concentrado sus investigaciones en el estudio de la cultura escrita entre la población guaraní durante el período colonial. Anteriormente, este investigador se había enfocado en el trabajo guaraní y en los conflictos fronterizos entre guaraníes y portugueses. Bajo la orientación de Andrea Daher, defendió en 2005 una tesis de doctorado en la Universidad Federal de Rio de Janeiro, titulada Práticas letradas guaranis: produção e usos da escrita indígena - Séculos XVII e XVIII. El libro que aquí reseñamos constituye precisamente una reorganización y reelaboración de la mencionada tesis de doctorado, que además incorpora material inédito no trabajado en la misma.

El libro contiene dos prefacios (escritos por Arno Alvarez Kern -miembro del jurado ante el cual Neumann defendió su tesis-y Guillermo Wilde), una introducción del autor, cinco capítulos y un breve epílogo. Cada uno de los capítulos concierne a un aspecto puntual de la cultura escrita guaraní. El primero de estos se centra en el idioma guaraní y en el complejo proceso que implicó, para los indígenas incorporados a las reducciones jesuíticas, el pasaje de una determinada tecnología de la comunicación -la oralidad- a otra -la escritura-. El segundo capítulo atañe a la relación entre la élite indígena y la cultura letrada. En él se elabora una tipología de delegaciones de la escritura y la lectura 
entre los indígenas (esto es, las diversas formas a través de las cuales podía establecerse un vínculo entre esa cultura letrada y los guaraníes no necesariamente alfabetizados).

3 A partir del tercer capítulo, Neumann explora los escritos producidos por los indígenas que se han conservado en archivos y bibliotecas. En este sentido, el tercer capítulo se centra en las cartas escritas por los guaraníes en el contexto creado por el Tratado de Límites entre las coronas de España y Portugal (1750) y la posterior Guerra Guaranítica (1753-1756). Al final de este capítulo, además, puede encontrarse una útil tipología de los documentos utilizados a lo largo de todo el libro (Neumann 2015, pp. 134-135). El cuarto presenta las prácticas de escritura guaraní vinculadas a la memoria, es decir, las producciones que hacían referencia a un tiempo cronológicamente pasado, como diarios y relaciones, entre otros. Para terminar, el quinto capítulo estudia la escritura guaraní después de la expulsión de los jesuitas de los territorios de la monarquía hispánica (1767-1768), con la consiguiente liberación de la élite indígena de los controles impuestos por estos misioneros. Asimismo, el libro contiene un índice de lugares y de pueblos indígenas y personas mencionadas a lo largo del texto, así como también diez reproducciones facsimilares de páginas de los documentos manuscritos o impresos trabajados. El libro es breve y, por esa razón, particularmente denso en cuanto al contenido trabajado, la información presentada y las interpretaciones construidas.

4 Tanto Letra de Índios como diversos artículos previos del historiador brasileño constituyen una expresión de novedades teóricas y de una nueva agenda de investigación desarrollada por la historia cultural. En efecto, desde la década de 1980 en adelante, la historiografía especialmente la europea- ha generado una renovación en la forma de estudiar la cultura a partir de objetos tales como la escritura, la lectura, el libro y las diversas prácticas asociadas a los mismos. Además de autores reconocidos como el francés Roger Chartier, resulta especialmente clara la influencia en la investigación de Neumann de la paleografía del italiano Adriano Petrucci y de la historia social de la escritura del español Antonio Castillo Gómez. Lo que estos autores han construido es una vía para estudiar las sociedades a través de las diferentes formas de producción, uso, apropiación y conservación de la cultura escrita, es decir, de los textos (y las prácticas que estos encierran) entendidos como síntomas de aspectos más amplios de la historia social y cultural. Solo en muy escasa medida estas nuevas propuestas de investigación habían sido utilizadas para estudiar la realidad colonial americana, y, mucho menos, su faceta específicamente indígena. Se encuentra aquí, pues, un aspecto no menor de la relevancia de la investigación del historiador brasileño.

5 Al mismo tiempo, aunque quizás indirectamente, la producción de Neumann guarda relación con las exploraciones centradas en la lengua guaraní, cuyo puntapié inicial se encuentra en la obra del jesuita Bartomeu Melià. Neumann aclara que su interés principal no reside específicamente en este idioma e indica que la guía para la elaboración de su corpus documental no estuvo determinada por dicha lengua sino por la práctica de escritura indígena (independientemente del o los idiomas en que se plasmase). Sin embargo, es imposible no establecer una relación con este campo de estudios, puesto que el historiador brasileño recupera la dimensión de materialidad -de soporte y de práctica cultural- que está necesariamente detrás de toda manifestación lingüística escrita. Debe destacarse, por lo demás, que la investigación sobre las misiones de guaraníes ha comenzado, en los últimos años, a prestar una atención cada vez mayor a esas manifestaciones lingüísticas. 
Como se ha señalado en el párrafo anterior, Neumann construye su corpus documental a partir de un criterio específico, el de la práctica escrituraria guaraní. La elaboración de este corpus no es una particularidad menor del libro, en la medida en que revela la existencia de documentos de este tipo e indica con claridad cuál es su carácter y en qué repositorio archivístico se conservan. En cierto sentido, el libro puede ser pensado como una extensa y detallada tipología de estos documentos. Entre la variedad de fuentes consultadas, Neumann se basa especialmente en billetes, cartas, memoriales, diarios, relatos personales, actas de cabildo y otros documentos de tipo manuscrito. Además, se utilizan como fuentes testimonios parciales referidos a prácticas letradas guaraníes contenidos en otros textos, por ejemplo referencias a la lectura y la escritura por parte de los indígenas (en textos jesuíticos), a prácticas de escritura expuesta e, incluso, a obras de narrativa histórica escritas por los guaraníes.

7 Los documentos consultados directamente (todos ellos del siglo XVIII, puesto que no se han conservado registros materiales de escritura indígena previos) fueron, en su mayoría, elaborados originalmente en guaraní, pero circularon acompañados de su traducción al castellano. En el caso de los textos relacionados con el Tratado de Límites y con la Guerra Guaranítica, fueron traducidos para ser enviados a la Península Ibérica como demostración de la participación de los guaraníes en el conflicto. Estas fuentes utilizadas por Neumann se encuentran esparcidas sobre todo en archivos de Argentina (Archivo General de la Nación y Museo Mitre) y España (Archivo General de Indias, Archivo General de Simancas, Archivo Histórico Nacional, Biblioteca Nacional de Madrid y Real Academia de Historia). Desde luego, Neumann focaliza en aspectos diferentes en cada uno de los análisis sobre fuentes puntuales; la unidad de su abordaje está determinada por la atención prestada a la práctica escritural y por la inscripción de esta práctica en la historia social y cultural de las reducciones de guaraníes.

8 El objetivo del libro es "analisar os usos, as funções e as praticas da escrita indígena nas reduções do Paraguai nos séculos XVII e XVIII” (Neumann 2015, p. 28). En este sentido, con respecto a este objetivo pueden identificarse tres ideas centrales que recorren toda la investigación. En primer lugar, Neumann enfatiza, en reiteradas ocasiones, que la alfabetización estuvo reducida a un determinado círculo dentro de la élite. Éste no necesariamente incluía a los caciques, estaba conformado por aquellos individuos que desempañaban funciones en el cabildo (como los secretarios) o que actuaban como maestros de capilla. Así, el historiador brasileño enfatiza el rol diferenciador que la educación jesuítica significó para estos sujetos, así como también el uso que hicieron de la alfabetización recibida en sus prácticas cotidianas. Ahora bien, es importante destacar que, como demuestra el autor, el hecho de que la alfabetización se redujera exclusivamente a este sector no significa que la relación con la cultura letrada quedase enmarcada solo en ese pequeño círculo: existían formas no escriturales de relacionarse con esta cultura, por ejemplo a través de las prácticas de delegación de la lectura y la escritura mencionadas. En segundo lugar, los guaraníes no escribieron exclusivamente obras de contenido religioso - por ejemplo, como los conocidos textos de Nicolás Yapuguay-. Neumann destaca la innumerable cantidad de temas que abordaron estos indígenas a través de su escritura, no solo en textos de escasa extensión como cartas y billetes (con finalidades casi siempre políticas y militares), sino también en producciones más elaboradas, por ejemplo textos de tipo protocolar, relatos personales y narrativa histórica. Neumann demuestra, de esta manera, que los indígenas trascendieron el 
entrenamiento y la educación propuestos inicialmente por los jesuitas como herramienta dentro de su estrategia evangelizadora.

En tercer lugar, Neumann revela que existieron momentos excepcionales en los cuales los guaraníes pudieron y quisieron ejercer con mayor fluidez el recurso a la escritura: así sucedió, en efecto, durante períodos de crisis y tensión, sobre todo después del Tratado de Límites y en el marco de la Guerra Guaranítica. El contexto crítico permitió una suerte de liberación de los indígenas respecto de los controles tradicionalmente ejercidos por los jesuitas. Además, a partir de mediados del siglo XVIII se inició un progresivo proceso de autonomía en la práctica escrituraria guaraní, desde luego acentuada en mayor medida después de la expulsión de los ignacianos de la monarquía hispánica. En cuarto lugar, Neumann subraya el modo en que la "razón gráfica" impactó y modificó características de una sociedad tradicionalmente constituida en la oralidad. A partir de la presencia y del accionar de los jesuitas, el guaraní se convirtió en una lengua "literaria" - es decir, con una literatura escrita-. Además, el pasaje de una tecnología de la comunicación a la otra modificó determinados aspectos de la cultura guaraní. Así sucedió con la constitución de una memoria indígena basada en el patrón temporal lineal occidental, que permitió, precisamente, la constitución de textos cronológicos y fundados en una datación precisa. Por medio de este tipo de textos, los guaraníes pudieron hacer referencia a diversos fenómenos históricos que juzgaron dignos de ser recordados: desde los servicios militares prestados a la monarquía hasta el cautiverio sufrido por un individuo puntual.

Las distintas ideas desplegadas por Neumann a lo largo del libro se enmarcan dentro de un planteo general que no debe ser ignorado: los guaraníes podían escribir, y efectivamente lo hicieron en función de sus propios intereses. Aún a pesar de que, en las últimas décadas, la historiografía ha tendido a reconocer, cada vez en mayor medida, que las poblaciones indígenas coloniales tenían actitudes de tipo racional y moderno, debe remarcarse la originalidad de esta idea, por cuanto retoma una de las principales prácticas de la cultura occidental -Michel de Certeau definió la escritura como una "práctica mítica moderna", fundante de la actividad "conquistadora" de Occidente- y demuestra el uso estratégico que los indígenas hicieron de la misma. De alguna manera, entonces, la obra de Neumann participa de un intento por rescatar las huellas, estrategias y actividades de los guaraníes del olvido de la historia. La elección de Nhanduti Editora especializada en textos sobre la cultura guaraní- como editorial para la publicación de este libro resulta, en este sentido, significativa: en una nota inicial, con que se abre el texto, los editores agradecen, utilizando el idioma guaraní, a los indígenas mencionados y citados, "en forma de memoria" ("mandu’apýramo"), a lo largo de toda la investigación (Neumann 2015, p. 10).

11 Por las razones enumeradas, el libro logra una densa descripción y clasificación de las distintas facetas que asumió la práctica de la escritura durante los siglos XVII y XVIII en las reducciones de guaraníes, antes y después de la expulsión de los miembros de la Compañía de Jesús. Neumann combina la exploración relativa a la capacidad de agencia de las poblaciones indígenas con las vetas novedosas abiertas por la nueva historia cultural en la agenda de investigación, de manera que revela características desconocidas e ignoradas incluso por los especialistas. Tanto por la originalidad de esta apuesta como por la generosidad con que se presentan los resultados y los documentos trabajados, el libro constituye una invitación para continuar explorando la historia de los intercambios y las apropiaciones culturales que tuvieron lugar en los "mundos mezclados" - para utilizar la expresión de Serge Gruzinski- de la modernidad temprana. 


\section{AUTHOR}

FABIÁN R. VEGA

Facultad de Filosofía y Letras, Universidad de Buenos Aires, Argentina Correo electrónico: vegafabianr@gmail.com 